\title{
Our psycho-neurodiabetological concept
}

\begin{abstract}
Since 2001 we know, that the blocking of the serotonin $2 \mathrm{C}, 3$ receptor can simultaneously decrease the production of the incretin hormones, ${ }^{1}$ this relates to the beta-cell-function ${ }^{2}$ nevertheless on a cellular level it also strenghtens the cellular insulin resistance. ${ }^{3}$ Perhaps this receptor is the central diabetes-controller-accordingly, maybe in both types of diabetes.
\end{abstract}

Keywords: vasopressin, serotonin, incretins, hypothalamus, neuroendocrinology, psychiatry, neurodiabetology, psychosomatics, diabetes
Volume 2 Issue 3 - 2015

Lehel Simon
Peter Mohos Entactex Pharma Research Project, Hungary

Correspondence: Lehel Simon, Entactex Pharma Research Project, Hungary, Debrecen, Tel +36 706625898

Email lehel.alpar@gmail.com

Received: June 02, 2015 | Published: July 27, 2015
Abbreviations: D4DR, dopamine d4 receptor gene; 5-HT receptors, serotonin receptors; GLP-1, glucagon-like peptide-1; DPP-4 Inhibitors, dipeptidyl peptidase 4 inhibitors; ACTH, adrenocorticotropic hormone; $\mathrm{CRH}$, corticotropin-releasing hormone

\section{Introduction}

Statistically, if someone takes clozapin for 3years, there is a $30 \%$ chance of a type two diabetes ${ }^{4}$ olanzapin is less agressive on this field ${ }^{5}$ but it is common in the USA that the psychiatrist - at his own discretion - gives a usual minidose of $2 \times 200 \mathrm{mg}$ metformin as an adjuvant. Interesting, that this diabetesizing effect regress after 2-3years and the increased body weight decrease even without metmorfin, there is 12 years of experience in this. However, it has only turned out from clozapin, which has been used since 1994. For example, risperidon slightly has such an effect, as it bonds to/with the 5-HT2C receptor much less, than to the 5-HT2A, it does not bond to the 5-HT3 receptor at all. ${ }^{6}$ But we must not forget, that diabetes one is an autoimmune disease. $^{7}$

\section{Discussion}

\section{Unusual Systems}

We must build upon the connection between the hypothalamus and the limbic system, through the vasopressin-dopamine-serotonin, etc. cycle, as the thermostatic function of the hypothalamus can control psychoimmune, e.g. autoimmune reactions: let us not forget the function of the nucleus supraopticus and the nucleus paraventricularis in the operation of secretin.

If we put the puzzle together, the beta-cell function and the incretins, and the inner dinamics of the peripherical insulin resistance, going back to the highest level of neuroendocrin and psychoimmune reactions and their probably - joint cerebral control - beyond the ordinary endocrinology, humorously: the insulin based diabetology gets replaced by a more complex neuroscience, where the insulin or the metmorfin means only a basic intervention.

\section{Our neurodiabetological concept in therapy too}

In the course of the research of the DPP-4 inhibitors today we can already talk about "incretin-axes". ${ }^{8}$ The glucagon-like peptide-1 (GLP-1) can be traced in the brain as well in a relatively high concentration, namely in the hypophysis, in the hypothalamus and in the nucleus reticularis thalami, a peptide consisting of 31 aminic acid.
It holds back the glucagon production of the alpha-cells, while it intensifies the insulin production of the beta-cells, but only in the basis of the ingested glucose, as it does not cause hypoglycemia, for which there are several enzime explanation as well, but I would also like to give a neural explanation for it in order to account for this hypothesis.

Because the ingested sugar releases insulin, which on the other hand releases serotonin in the dorsal and medial raphe nuclei. Accordingly, the 5-HT2C, 3 activity increases, which results in more incretins: therefore the cerebral and medical process are already synchronized here. The endorphine excess presses down ${ }^{9}$ the hypothalamicalhypophyseal D4 and V3 activity. ${ }^{10}$ Glucose creates a state of mentalphysical satisfaction. At the same time GnRH also increases, as it does not get press down by endorphine, that is, the neuroendocrin "pleasure-seeking" begins again.

The low V3 vasopressin receptor activity (unstressed entactogenesis), ${ }^{11}$ high D4 dopamine receptor activity (especially the length ofD4DR candidate gene: adventure seeking) ${ }^{12}$ and low serotonin level (dissatisfaction) ${ }^{13}$ result in a new endorphine cyle, which, in order to be self-sufficient require sugar again, the $\mathrm{CRH}-\mathrm{ACTH}$-adrenalinecorticosteroid axis increases with the beta endorphine, once again "demanding" sugar.And this complex neuroendocrinological cycle reproduces itself. Thus the incretin system has a very serious neural controller as well, in accordance with endocrinology, quasi in sync.

So much the more as the cycle's main neurochemical switches the: "I am open, I am looking for new ways" vasopressin in the brain, the "I want" dopamine, the "I am enjoying it" endorphine, and "the sugar has come, I am satisfied" serotonine can be related to psychological states. But the cycle's balance can be disrupted both in neural and endocrine way, e.g. "I am starving", "I suffer from bulimia".

On the basis of our current knowledge this searching cycle is probably opened by the cerebral vasopressin, whose receptors, the $\mathrm{V} 1 / \mathrm{V} 3$, can be found in the hypothalamus and in the hypophysis, also where GLP-1 is; and GLP-1 can also be found in the nucleus reticularis thalami, which region is the afferentationial center between the brainstem (see serotonin-raising) and the cortex (see endorphinerelease). Is it a coincident?

The DPP-4 inhibitors are trerating diabetes innovatively, perhaps with the V1/V3-regulating the psychological desire for sugar could be increased or reduced in eating disorders, so, that we are in control of the whole chain of neuro-diabetes, and not only in the way that is widely known, but in the way, that we invasively dive into more 
invasive serotonin-systems (see sibutramine), ${ }^{14}$ presumably more complexly, naturally and with less side effects.

\section{Conclusion}

According to our supposition, this not only could play a role in the reducement of appetite as sibutramine in the appropiate biofeedbackcycle can even treat the psychological increase of appetite, but the neuroendocrine incretinerg and even the medical alpha, beta-cell function can too be positively influanced with it: it would be a theoretical combination of 5-HT2C agonist lorcaserin, ${ }^{15}$ sibutramine, metmorfin and the therapies after metmorfin, between Psychiatry and Neuroendocrinology. ${ }^{16}$

\section{Acknowledgements}

None.

\section{Conflict of interest}

Auhtor declares that there is no conflcit of interest.

\section{References}

1. Hurley JH, Zhang S, Bye LS, et al. Insulin Signaling Inhibits the 5-HT2C Receptor in Choroid Plexus Via MAP Kinase. BMC Neurosci. 2003;9:4-10.

2. Date M, Matsuzaki K, Matsushita M, et al. Modulation of Transforming Growth Factor B Function in Hepatocytes and Hepatic Stellate Cells in Rat Liver Injury. Gut. 2000;46(5):719-724.

3. Dunaif A, Segal KR, Futterweit W, et al. Profound Peripheral Insulin Resistance, Independent of Obesity, in Polycystic Ovary Syndrome. Diabetes. 1989;38(9):1165-1174.

4. Koller E, Schneider B, Bennett K, et al. Clozapine-Associated Diabetes. Am J Med. 2001;111(9):716-723.
5. Praharaj SK, Jana AK, Goyal N, et al. Metformin for Olanzapine-Induced Weight Gain: A Systematic Review and Meta-Analysis. Br J Clin Pharmacol. 2011;71(3):377-382.

6. Abel Lajtha, Daniel Javitt, Joshua Kantrowitz. Handbook of Neurochemistry and Molecular Neurobiology. Springer; 2009;12-45.

7. Gazda LS, Baxter AG, et al. Regulation of Autoimmune Diabetes: Characteristics of Non-Islet-Antigen Specific Therapies. Immunol Cell Biol. 1996;74:401-407.

8. Ahren B, Schmitz O. GLP-1 Receptor Agonists and DPP-4 Inhibitors in the Treatment of Type 2 Diabetes. Horm Metab Res 2004;36(11-12):867-876.

9. Colameco S, Coren JS. Opioid-Induced Endocrinopathy. J Am Osteopath Assoc. 2009;109(1):20-25.

10. Boulant JA. Role of the Preoptic-Anterior Hypothalamus in Thermoregulation And Fever. Clin Infect Dis. 2000;5:157-161.

11. Rene P, Grino M, Viollet C, et al. Overexpression of the V3 Vasopressin Receptor in Transgenic Mice Corticotropes Leads to Increased Basal Corticosterone. J Neuroendocrinol. 2002;14(9):737-744.

12. Paterson AD, Sunohara GA, Kennedy JL. Dopamine D4 Receptor Gene: Novelty or Nonsense? Neuropsychopharmacology. s1999;21(1):3-16.

13. Song Z, Li W, Arvey RD. Associations between Dopamine and Serotonin Genes and Job Satisfaction: Preliminary Evidence from the add Health Study. J Appl Psychol. 2011;96(6):1223-1233.

14. Arajúo JR, Martel F. Sibutramine Effects on Central Mechanisms Regulating Energy Homeostasis. Curr Neuropharmacol 2012;10(1):49-52.

15. Aronne L, Shanahan W, Fain R, et al. Safety and Efficacy of Lorcaserin: a Combined Analysis of the BLOOM and BLOSSOM Trials. Postgrad Med. 2014;126(6):7-18.

16. Lehel Simon. Application for the development of a new autism medicine. Budapest. Entactex Pharma Research Project, Debrecen, Hungary; p. $20-45$ 